\title{
The Relationship Structure of Global Exchange Rate Based on Network Analysis
}

\author{
Hongduo Cao*, Zerui Guo, Ying Li*, Zhouzhou Ran \\ Sun Yat-sen Business School, Sun Yat-sen University, Guangzhou, China \\ Email: *caohd@mail.sysu.edu.cn, *mnsliy@mail.sysu.edu.cn
}

How to cite this paper: Cao, H.D., Guo, Z.R., Li, Y. and Ran, Z.Z. (2020) The Relationship Structure of Global Exchange Rate Based on Network Analysis. Journal of Mathematical Finance, 10, 58-76.

https://doi.org/10.4236/jmf.2020.101006

Received: April 19, 2019

Accepted: January 19, 2020

Published: January 22, 2020

Copyright $\odot 2020$ by author(s) and Scientific Research Publishing Inc. This work is licensed under the Creative Commons Attribution International License (CC BY 4.0).

http://creativecommons.org/licenses/by/4.0/

\begin{abstract}
The optimal threshold strategy is put forward for establishing a suitable network for analyzing the correlation among the different exchange rates. The 33 currencies of the world's major countries and regions are analyzed by the method of network analysis, and the multilateral exchange rate correlation network is established based on the optimal threshold. Combining with geographical features and the exchange rate regime, it is found that the international currency has obvious community structure, which is composed of three levels: the core currency area, the arbitrage currency area and the shadow currency area. The conclusion reveals the structural characteristics of the Jamaica international monetary system.
\end{abstract}

\section{Keywords}

Exchange-Rate Relationships, Correlation Networks, Complex Networks, Geopolitical Features

\section{Introduction}

33 currencies of the world's major countries and regions are analyzed by the method of network analysis, and the multilateral exchange rate correlation network is established based on the optimal threshold. Our research found that due to the economic and trade characteristics and international political status of countries as well as the choice of exchange rate regimes in countries, 3 major levels are finally displayed in the overall network of exchange rates. One of these levels is USD-centered USD core area that is composed of Renminbi and oil currency, and its periphery is composed of the consumption-based currencies in the Eurozone and upstream resource-based currencies, such as Indonesian rupiah and Australian dollar; the second level is the arbitrage currency that is represented by Japanese Yen and Australian Dollar; and the third level is Korean won and U.K. pound as shadow currency. Correlation structure for the currency exchange rate 
of various countries shows a regional feature and has obvious geographical characteristics. Our research showed that the choice of exchange rate regimes in countries is the result of differences in economic development and economic system and the characteristics of international trade as well as the result for location choice of country's currency in international monetary system. The research section in this paper reveals the structural characteristics of international monetary system under the Jamaica system with USD as the core ${ }^{1}$.

\section{Literature Review}

Analysis of bilateral relations based on exchange rate has gradually formed the purchasing power parity theory that reflects equilibrium of commodity markets, the interest rate parity theory that reflects equilibrium of asset markets, and the asset market theory that is determined by exchange rate under the floating exchange rate regime in the general equilibrium analysis determined by integrating these two preconditions into exchange rate. These theories don't give a final solution to the so-called "mysteries of exchange rate" such as "deviation of exchange rate from fundamentals", "excessive exchange rate fluctuations", and "non-linear exchange rate fluctuations". As a universal equivalent, currency naturally has the properties of network. The exchange rate theory based on bilateral relations hasn't paid sufficient attention to the peculiar property of monetary network. Under the background of deepening international trade and capital flow, the monetary network property inevitably forms an associated network in which the exchange rate (currency price) fluctuates. Based on the multiple correlations of exchange rate, this paper extracts and analyzes characteristics of the whole correlation network of exchange rate fluctuations and studies the formation and mechanism, which is beneficial to the better understanding of the complexity of exchange rate fluctuations.

The method of network analysis adheres to Aristotle's holistic theory at the philosophical level and has an obvious methodological "structure-function" characteristic. In the research, the network analysis establishes a network model with the studied individuals as nodes and connection between individuals as the side. At mathematics, it belongs to the "graph theory" network model. For network analysis, there are two research paradigms: social networks and complex networks (Jackson, 2008), and Yang Jianmei (2010) thinks that there is a tendency that the two coexistent research paradigms narrow differences and converge [1] [2]. Social network analysis began with the study of social metrology and group dynamics in the 1930s. By 1969, the anthropologist Mitchell (1969) proposed a systematic framework for social network analysis [3], and then it was matured through the mathematic deepening by White in Harvard to form a con-

\footnotetext{
${ }^{1}$ In January 1976, the "Interim Committee on the International Monetary System" of the Board of Governors of the International Monetary Fund (IMF) held a meeting in Kingston, the capital of Jamaica, to discuss the terms of the IMF Agreement and sign the "Jamaica Agreement". In April of same year, the Board of Governors of IMF adopted the Second Amendment to the IMF Agreement, confirmed the legalization of the floating exchange rate regime, and formed a new international monetary system.
} 
temporary social network analysis (Scott, 2000) [4]. Social networks generally focus on studying social relationships and name them after these research objects, such as Granovetter's (1973) study of weak link information superiority theory [5]. In macroeconomic governance and financial market micro analysis, social network is a research method and a research object. For example, Cohen, Frazzini, and Malooy (2008) used educational background as a proxy variable for social relations to study the effect of social networks on asset prices [6]. Zhang Min, Tong Lijing and $\mathrm{Xu}$ Haoran (2015) studied the role of social networks in corporate risk sharing with their employment experience as proxy variables [7]. This type of research focuses on social relations and "metaphorizes" it as the network connection, but it is subjective to certain extent in setting of relational proxy variables.

Complex network research starts with statistical physics and complexity science, and is marked by two groundbreaking research efforts: small-world network theory (Watts \& Strogatz, 1998) [8] and scale-free network theory (Barabasi \& Albert, 1999) [9]. The geometrical nature of complex network analysis makes it has the advantages of natural visualization; at the same time, adjusting the network structure according to the "connection" strength, enables the complex network analysis to effectively carry out the dimensionality reduction analysis for data, which also becomes a kind of method for data mining. For complex network paradigm, there are 3 ways in the network construction: the way based on the existing real relationship, the way of building based on theory, and the way based on data. Complex network itself is the complex representation for temporal and spatial evolution of nature and human society, which also exists in economic and financial systems. For example, Glasserman and Young (2015) studied the European interbank lending network and found that the expected loss caused by network effect is very small when there is no significant difference in bank sizes that are highly dependent on interbank market financing [10]. Based on shareholding relationship, Yan et al. (2015) analyzed the shareholdings of U.S. corporations in the "Fortune Global 500" through complex network models [11]. With difficulty of acquiring relational data in reality, it is an important direction to analyze the network structure, characteristics and effect based on theory-based network building. Nier et al. (2007) refined 4 typical risk transmission mechanisms in financial networks through theoretical modeling [12]. Li Ying, Cao Hongduo and Xing Haoke (2012) used the agent-based computational experiments to analyze the roles and different market effects of learning mechanism, learning structure and duration strategy in the game for 3 networks: stochastic, small-world and scale-free networks [13].

Data-based network analysis is getting more and more attentions because of its independence from algorithms and models. Li Zheng, Liang Qi and Tu Xiaofeng (2015) constructed a related network of listed financial institutions in China from 2008 to 2015 from the perspective of information overflow, and deconstructed the overall relevance and interdepartmental and departmental correlation characteristics of financial networks [14]. Zhang Laijun, Yang Zhihui and 
Lu Feifei (2014) constructed a network based on fluctuation correlation of the stock market to study correlation of stock indexes [15]. Big data weakens the causal relationship and pays more attention to mining the correlation between different factors. At present, there are mainly two methods for network construction that are based on data dependency. Mantegna (1999) established a minimum spanning tree (MST) based on the stock network. MST network is concise and intuitive, and provides a new perspective for the networked research of financial market [16].

Johnson and McDonald (2005) used MST method to study the dynamic causes of exchange rate network, scrutinize the dominant currency and dependent currency, and find that the exchange rate network is very geographical [17]. Naylor (2007) used MST and hierarchy tree method to study the foreign exchange market from 1995 to 2001 and found a clear and steady scale-free network, and studied the crisis transmission path during the Asian financial crisis to find that the crisis transmission influences other countries mainly via USD rather than having a direct impact [18]. Keskin (2011) MST studied the network and hierarchy structures of 34 major currencies using MST with USD and Turkish lira as the base currencies respectively, and verified the view that the major currencies come from countries participating in the world's major economic events [19]. Despite MST network is simply, it filters out a great deal of important information during building network. Boginski (2005) applied threshold method for building network to the financial market for the first time: by building correlation coefficient matrix C_(i, j) for the daily returns of each stock in the U.S. stock market, the adjacency matrix D was built. Studies found that stock market network complies with power-law distribution and shows the scale-free property [20]. Kwapień, Gworek and Drożdż (2009) used threshold method to study the foreign exchange market that includes 63 currencies including precious metals, and screen the closely connected currencies [21]. The key to build network via the threshold method is to choose a suitable threshold $\theta$ so that network structure reflects characteristics of the market. If the threshold chosen is too small, the effective structure can't be highlighted; the network filters a large amount of information if it's too small. Therefore, choosing an appropriate threshold is very important for building network. This paper presents an optimal method for setting threshold, and accordingly conducts network analysis on the opposite side exchange rate structure.

\section{Data and Network Modeling}

Data are sourced from the statistical database of the International Monetary Fund (IMF) and include daily exchange rate data from 33 countries. By considering the international recognition of currency, [19] established two MST networks with USD and Turkish lira as the benchmark currencies, while others chose precious metal as the benchmark. The benchmark used in this paper is the Special Drawing Rights (SDR). We selected the data from June 2003 to May 2013. Table 1 shows the currencies and abbreviations of 33 countries and regions. 
Table 1. Table of currencies and abbreviations.

\begin{tabular}{cccc}
\hline Currencies & Currency Codes & Currencies & Currency Codes \\
\hline Australian dollar & AUD & Malaysian ringgit & MYR \\
Brazilian real & BRL & Mexican peso & MXN \\
CAD & CAD & New Zealand dollar & NZD \\
Chilean peso & CLP & Norwegian krone & NOK \\
Chinese yuan & CNY & Pakistani rupee & PKR \\
Colombian peso & COP & Polish zloty & PLN \\
Czech koruna & CZK & Qatar riyal & QAR \\
Danish krone & DKK & Russian ruble & RUB \\
Euro & EUR & Saudi Arabian riyal & SAR \\
Hungarian forint & HUF & Singapore dollar & SGD \\
Indian rupee & INR & South African rand & ZAR \\
Indonesian rupiah & IDR & Swiss franc & CHF \\
Iranian rial & IRR & Thai baht & THB \\
Israeli new sheqel & ILS & U.A.E. dirham & AED \\
Japanese yen & JPY & U.K. pound & GBP \\
Korean won & KRW & U.S. dollar & USD \\
Kuwaiti dinar & KWD & & \\
\hline & & &
\end{tabular}

The method adopted in this paper was to establish a network with threshold method. The basic idea was to select an appropriate threshold $\theta$ based on the correlation coefficient matrix that is formed by $N$ return rate series. If the correlation coefficients of two nodes $(i, j)$ exceeded $C_{i j} \geq \theta$, the two nodes $(i, j)$ were considered as being connected with each other, which are represented as a connection in the network diagram and represent an element $A_{i j}=1$ in the adjacency matrix $A$; if $C_{i j}<\theta$, the two nodes $(i, j)$ were not considered to be connected, which are represented as a non-connection in network diagram and represent an element $A_{i j}=0$ in the adjacency matrix $A$. If $P_{i}$ was the daily return rate of the $i^{\text {th }}$ currency, $i=1, \cdots, 55$. We could establish the daily corresponding logarithmic return rate series:

$$
R_{i}(t)=\ln P_{i}(t+1)-\ln P_{i}(t)
$$

And establish a correlation coefficient matrix $C$ with the correlation coefficient matrix $33 \times 33$.

$$
c_{i j}=\frac{\operatorname{Cov}\left(R_{i}, R_{j}\right)}{\sqrt{\operatorname{Var}\left(R_{i}\right) \cdot \operatorname{Var}\left(R_{j}\right)}}
$$

The research in this paper focuses on the correlation of exchange rates. Therefore, the absolute-valued correlation coefficient matrix was used as the basis for network building via the threshold method: $C_{a b s}=|C|$. A total of 120 correlation coefficient matrices were monthly created for data of all trading days in a total of 120 months from June 2003 to May 2013, and each correlation coeffi- 
cient matrix had $528(33 \times 32 / 2)$ valid correlation coefficients. A statistical description of all the correlation coefficients is shown in Figure 1.

Average of correlation coefficient was 0.107040 that reflects positive correlation of world exchange rate network as a whole. There are mainly two reasons for this: firstly, the economic globalization is more manifested in that the complementarity of economy and trade among cooperative countries is greater than the competition; secondly, it is the benchmark currency's coupling of SDR. Overall coupling effect among currencies is enhanced and network links are more closely.

From disorder to order, the power-law phenomenon exists generally. Barabasi (2002) pointed out that the power law is a sign for the self-organization of complex systems [22]. Power law can be used as the inherent geometric invariance of economic system complexity. Cao Hongduo et al. (2013) put forward the optimal method for determining threshold based on empirical analysis [23]. It was found that increase of the threshold $\theta$ can enhance the power-law fitting and help highlight the inherent invariance. Meanwhile, with increase of threshold, the connection between some nodes was removed, which reduces the overall information. To balance the integrity and validity of network information, the optimal threshold index $W$ is as follows after two indexes $N$ and $R^{2}$ were normalized in this paper:

$$
W\left(N, R^{2}\right)=\left(N / N_{\text {all }}\right) \times R^{2}
$$

where, $N(\theta)$ and $R^{2}(\theta)$ are the number of nodes and goodness of fit, which are functions of $\theta, W\left(N, R^{2}\right)$ is a complex function $g(\theta)$ of $\theta$. If $\theta^{*}$ exists, which makes $g^{\prime}\left(\theta^{*}\right)=0$ and $g^{\prime \prime}\left(\theta^{*}\right)<0, g(\theta)$ has the maximum value $g(\theta)_{\max }=g\left(\theta^{*}\right)$, and the corresponding $\theta^{*}$ is the optimal threshold.

For example, the correlation coefficient $C_{a l l}$ is established under time window from June 1, 2003 to May 31, 2013, and the related network connection matrix of exchange rate fluctuation $A_{\text {all }}$ is established, where,

$$
\left(A_{\text {all }}\right)_{i j}= \begin{cases}1, & \left|\left(C_{a l l}\right)_{i j}\right| \geq \theta \\ 0, & \left|\left(C_{a l l}\right)_{i j}\right|<\theta\end{cases}
$$
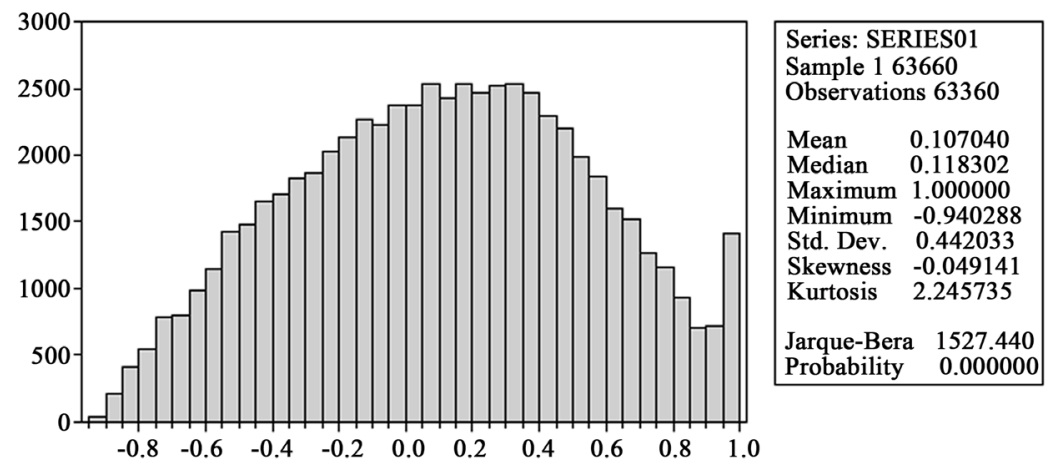

Figure 1. Statistical result description of correlation coefficients of return rate on the monthly exchange rate. 
The number $N(\theta)$ of nodes in all networks was examined: as the threshold $\theta$ increased, the number of network nodes decreased after the threshold $\theta>0.17$. When the threshold $\theta>0.44$, the number of nodes in the network dropped below 20 and the integrity of exchange rate network was destroyed, as shown in Figure 2.

The power-law distribution goodness-of-fit of all networks $R^{2}(\theta)$ was examined: the exchange rate network had only 33 nodes in the case of full connection, so the power-law goodness-of-fit curve fluctuated greatly. The power-law distribution goodness-of-fit $R^{2}$ kept rising when the threshold $\theta$ increased from 0 to 0.36 , and increased unsteadily when the threshold $\theta$ increased from 0.36 to 0.74 , and the power-law distribution goodness-of-fit rose gradually when it increased from 0.74 to 0.98 . However, there are fewer than 10 network nodes only. Original structure of the entire exchange rate network had been destroyed at this time, as shown in Figure 3. The optimal threshold index $W$ of exchange rate network under different thresholds is shown in Figure 4.

The optimal threshold for the static network established under time window from June 1, 2003 to May 31, 2013 was $\theta^{*}=0.34$, the number of nodes still remained in network was 31, and integrity of network was well preserved. The network connection at this time is shown in Figure 5.

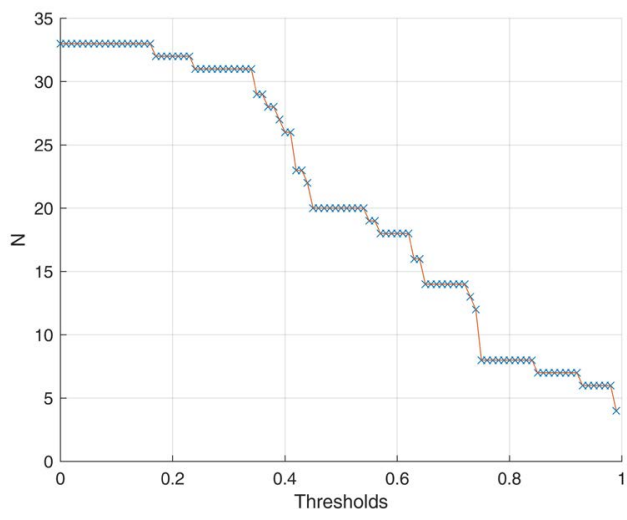

Figure 2. The number of nodes $N$ of static exchange rate network under different thresholds.

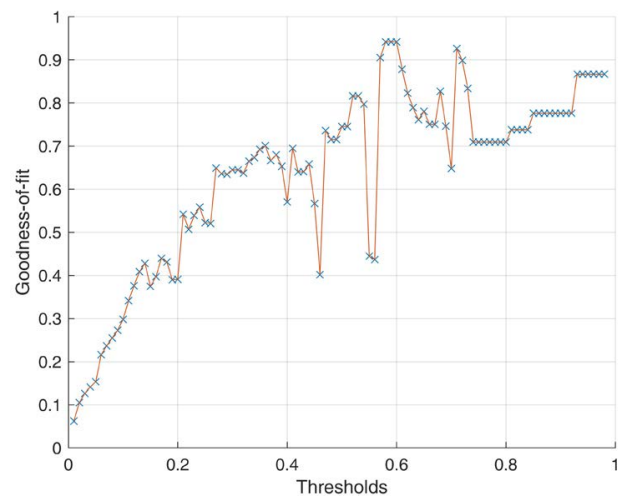

Figure 3. Power-law distribution goodness-of-fit $R^{2}$ of static exchange rate network under different thresholds. 


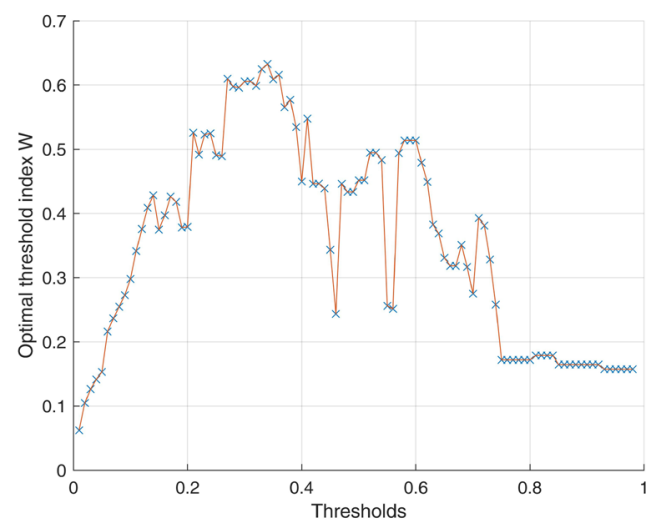

Figure 4. Optimal threshold index $W$ of the exchange rate network under different thresholds.

O IRR

OILS

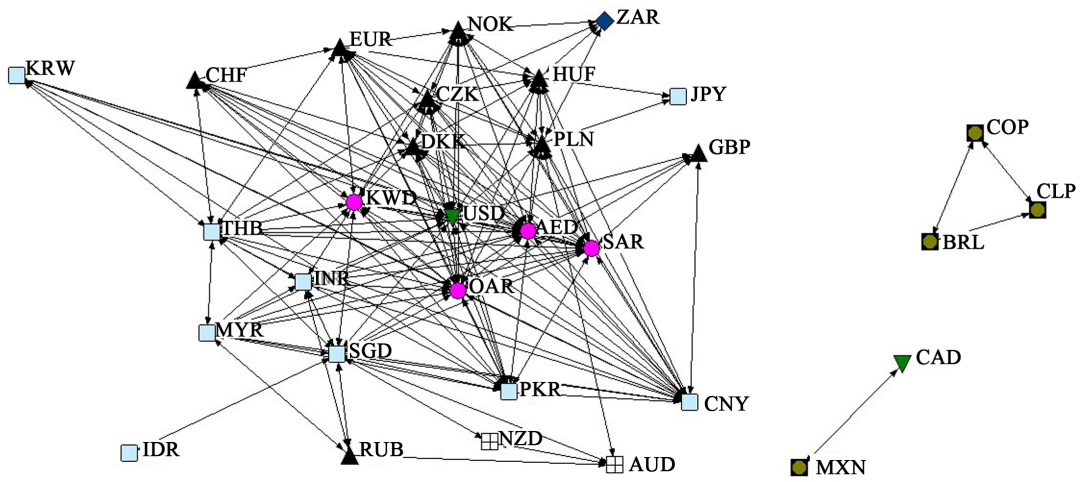

Figure 5. Exchange rate network diagram under the optimal threshold (geographical factors).

\section{Analysis on Geographical Characteristics and Exchange Rate System Arrangements of Multilateral Exchange Rate Network}

The topological structure of the network established under time window from June 1, 2003 to May 31, 2013 was analyzed. As shown in Figure 5, the currencies of the two Middle East countries-Iran and Israel-were completely isolated, but all other nodes maintained certain connection. 3 South American countries-Colombia, Chile and Brazil, were interconnected but separated from other nodes, the remaining nodes constituted a component with higher connectivity and more complicated connection. This paper analyzed the topology of full-time exchange rate network in combination with geographical characteristics and impact of exchange rate regime.

\section{1) Analysis of geographical characteristics}

The source matrix Dis $(33 \times 7)$ was established based on the areas to which 33 nodes belong. Columns of the matrix respectively represented West Asia, Asia (excluding West Asia), Europe, Oceania, North America, South America and Africa. 


$$
\operatorname{Dis}_{i j}= \begin{cases}1, & \text { if currency } i \text { is in region } j ; \\ 0, & \text { if currency } i \text { isn't in region } j .\end{cases}
$$

There were two considerations for the division of Asia: there were many nodes in Asia selected in this paper, and it was difficult to show the geopolitical characteristics of the exchange rate network without subdividing nodes in the region. Asia was divided into two parts-West Asia and Asia (except West Asia) because the political and economic factors for the two regions are quite different. What is most concerned about in this paper is exchange rate market. The selected West Asian countries are actually representatives of the Middle East countries that control most of the world's oil resources. Among the 6 countries, 5 countries (except Israel) are major members of OPEC (Organization of Petroleum Exporting Countries) that are composed of 12 countries; while the rest of Asia are countries in East Asia, South Asia and Southeast Asia. Although there are quite different political and economic factors in these regions, the overall difference is even more significant as compared to West Asia.

Let's A_Dis $=\operatorname{Dis}^{\mathrm{T}} \cdot\left(A_{\text {all }} \cdot\right.$ Dis $)$. Where, $A_{\text {all }}$ is connection matrix of the established exchange rate network. The A_Dis's elements A_Dis ${ }_{i j}$ indicate that the number of connections from area $i$ to area $j, \mathrm{~A}_{-} \mathrm{Dis}_{i j}=\mathrm{A} \_$Dis ${ }_{j i}$ as undirected networks were used, and A_Dis ${ }_{i i}$ means twice that of the number of interconnections in same area.

The number of nodes in various areas is different. To horizontally compare the density of connections in different areas, a standardized approach was adopted as follows: For the intra-area connections, namely A_Dis ${ }_{i i}$, the following method was used for standardization:

$$
\text { A_Dis_Std }{ }_{i i}= \begin{cases}\frac{\text { A_Dis }_{i i}}{N_{i} \times\left(N_{i}-1\right)}, & \text { if } N_{i}>1 \\ 0, & \text { if } N_{i}=1\end{cases}
$$

where, $N_{i}$ is the number of nodes in the $i^{\text {th }}$ area. In particular, there was only one node in Africa, so there was no connection in this area.

For the connections between area $i$ and area $j$, namely A_Dis ${ }_{i j}$, the following method was used for standardization:

$$
\text { A_Dis_Std }{ }_{i j}=\frac{\text { A_Dis }}{i j}
$$

A_Dis_Std is defined as the inter-area fluctuation correlation matrix, A_Dis_Std ${ }_{i j}$ is the relative fluctuation correlation between area $i$ and area $j$. A_Dis_Std is shown in Table 2. The areas of 33 countries were grouped according to Table 3. The network structures after considering the geographical factors are shown in Figure 5.

Coupled with geopolitical consideration, the network structure was clearer. Except that two Middle East countries-Iran and Israel in the entire network have no connection with other countries, the other nodes were divided into 3 components: Mexico and Canada was connected with each other, but separated 
Table 2. Standardized connection matrix among areas.

\begin{tabular}{cccccccc}
\hline & $\begin{array}{c}\text { West } \\
\text { Asia }\end{array}$ & $\begin{array}{c}\text { Asia } \\
\text { (except } \\
\text { West Asia) }\end{array}$ & Europe & Oceania & $\begin{array}{c}\text { North } \\
\text { America }\end{array}$ & $\begin{array}{c}\text { South } \\
\text { America }\end{array}$ & Africa \\
\hline West Asia & 0.40 & 0.50 & 0.54 & 0.00 & 0.33 & 0.00 & 0.00 \\
Asia (except West Asia) & 0.50 & 0.50 & 0.26 & 0.11 & 0.39 & 0.00 & 0.00 \\
Europe & 0.54 & 0.26 & 0.47 & 0.11 & 0.44 & 0.00 & 0.44 \\
Oceania & 0.00 & 0.11 & 0.11 & 1.00 & 0.00 & 0.00 & 0.00 \\
North America & 0.33 & 0.39 & 0.44 & 0.00 & 0.00 & 0.13 & 0.00 \\
South America & 0.00 & 0.00 & 0.00 & 0.00 & 0.13 & 0.50 & 0.00 \\
Africa & 0.00 & 0.00 & 0.44 & 0.00 & 0.00 & 0.00 & 0.00 \\
\hline
\end{tabular}

Table 3. Area division diagram.

\begin{tabular}{cccccccc}
\hline Areas & $\begin{array}{c}\text { West } \\
\text { Asia }\end{array}$ & $\begin{array}{c}\text { Asia } \\
\text { (except } \\
\text { West Asia) }\end{array}$ & Europe & Oceania & $\begin{array}{c}\text { North } \\
\text { America }\end{array}$ & $\begin{array}{c}\text { South } \\
\text { America }\end{array}$ & Africa \\
\hline Number of nodes & 6 & 9 & 9 & 2 & 2 & 4 & 1 \\
Symbol representation & 0 & $\square$ & $\mathbf{N}$ & $\square$ & $\nabla$ & $\square$ & \\
\hline
\end{tabular}

with other nodes; South American countries-Colombia, Brazil and Chile were connected with each other, but separated with other nodes; the largest component included all Asian (except West Asia) nodes, European nodes, the rest West Asian nodes, and the United States and South Africa.

Oceania had a highest fluctuation correlation (1.00) in terms of connection strength because it had only two nodes that are connected with each other. But, Oceania had very weak connection with other areas, and had only weak connections with Europe and Asia (except West Asia). Although Asia (except West Asia) had a highest number of nodes among all areas, it had the fluctuation correlation strength up to 0.50 , which shows that the fluctuation correlation effect among currencies of Asia (except West Asia) is relatively strong, and Asian currencies are also more strongly associated with the fluctuations in countries beyond South America and Africa, and the correlation strength (0.5) with West Asia is even higher than that within West Asia (0.4). The fluctuation correlation strength within South America was same to that in Asia. Three of the four nodes were fully connected. But South America was relatively independent and had only a weak connection with North America. The intra-European correlation strength was higher (0.47), and there was a stronger correlation with North America, Africa and West Asia, of which the Europe's correlation strength with West Asia exceeded that within Europe; the internal connection strength in West Asia, and the internal connection strength with Europe, North America and Asia (except West Asia) were stronger, which shows that the entire West Asia region has a strong connectivity in the network and plays a bridging role, but there is no connection between this area and Oceania, South America or Africa. There were 
only two countries in North America-the United States and Canada and they had a poor inter-area connectivity and stronger connections with West Asia, Asia (except West Asia) and Europe (0.33, 0.39 and 0.44). All connections in this area came from USD, and CAD only connected with Mexico peso, reflecting USD's core position in the network. As the most marginal part of the network, Africa was only connected with Europe. It was noteworthy that South African currency ZAR was connected with 4 European currencies but not connected with euro and USD.

Overall, except for Africa and North America, currencies in other areas had a higher internal fluctuation correlation strength, which reflects the geography of currencies. For Africa, it couldn't reflect the internal connection of currencies within Africa because only one node was selected, so there may be more comprehensive conclusions if we thought about other currencies in Africa. For external connections, there were stronger external correlation strengths among Europe, Asia (except West Asia), West Asia, and North America. The geographical characteristics of exchange rate network reflect the economic and trade ties among areas, and the political, economic and historical factors behind them deserve further consideration.

\section{2) Analysis on impact of exchange rate regime}

The tripartite paradox proposed by Paul Krugman (1999) on the basis of Mundell-Fleming Model states that one country can only choose two among the exchange rate stability, free flow of capital and independence of monetary policy [24]. Therefore, one country also determines its capital mobility and monetary policy independence when choosing the exchange rate regime. According to the de facto exchange rate regime classification of IMF annual reports (Classification of Exchange Rate Arrangements and Monetary Policy, IMF Annual Report, 2004, 2006, 2008, 2010, 2012) [25] and the three-kind division standards of exchange rate regime conducted by Von Hagen and Zhou (2007) on basis of the IMF de facto exchange rate regime [26], the exchange rate arrangements of currencies are shown in Table 4.

In the exchange rate policy arrangements under 3 major categories, the currencies of the selected 33 countries and regions didn't use the pegged exchange rate policy, about 25 nodes used the floating exchange rate regime, and the rest used the intermediate exchange rate regime. After the financial crisis of 2008, the currencies with change from the intermediate exchange rate regime to the floating exchange rate regime increased. In particular, PKR, RUB and IRR switched from the intermediate exchange rate regime to the floating exchange rate regime, and chose the floating exchange rate regime again after 2008. Overall, the network de facto exchange rate regime that is adopted in relatively central nodes in the network remained unchanged from 2004 to 2012. Changes in the exchange rate policy in each year are shown in Table 5.

3) Comprehensive analysis of geopolitical nature and exchange rate regime

a) Currencies of South America 
Table 4. Exchange rate policy change schedule of currencies.

\begin{tabular}{|c|c|c|c|c|c|c|}
\hline \multirow{2}{*}{$\begin{array}{l}\text { Exchange } \\
\text { rate regime } \\
\text { arrangements }\end{array}$} & \multicolumn{2}{|r|}{2004} & \multicolumn{2}{|r|}{2006} & \multicolumn{2}{|r|}{2008} \\
\hline & Qty. & Currencies & Qty. & Currencies & Qty. & Currencies \\
\hline Hard pegs & 0 & - & 0 & - & 0 & - \\
\hline $\begin{array}{l}\text { Intermediate } \\
\text { exchange } \\
\text { rate regime }\end{array}$ & 8 & $\begin{array}{l}\text { CNY, MYR, } \\
\text { QAR, SAR, } \\
\text { AED, DKK, } \\
\text { HUF, KWD }\end{array}$ & 8 & $\begin{array}{l}\text { CNY, KWD, } \\
\text { PKR, QAR, } \\
\text { SAR, AED } \\
\text { DKK, } \\
\text { HUF, IRR }\end{array}$ & 9 & $\begin{array}{l}\text { DKK, KWD, } \\
\text { PKR, QAR, } \\
\text { RUB, SAR, } \\
\text { AED, } \\
\text { CNY, IRR, }\end{array}$ \\
\hline $\begin{array}{l}\text { Floating } \\
\text { exchange } \\
\text { rate regime }\end{array}$ & 25 & $\begin{array}{l}\text { CZK, INR, IDR, } \\
\text { IRR, PKR, RUB, } \\
\text { SGD, THB } \\
\text { AUD, BRL, CAD, } \\
\text { CLP, COP, EUR, } \\
\text { ILS, JPY, KRW, } \\
\text { MXN, NZD, } \\
\text { NOK, PLN, ZAR, } \\
\text { CHF, GBP, USD }\end{array}$ & $\begin{array}{l}\mathrm{II} \\
\mathrm{A} \\
\mathrm{C} \\
\mathrm{I} \\
\mathrm{N} \\
\mathrm{C}\end{array}$ & $\begin{array}{c}\text { COP, CZK, } \\
\text { INR, MYR, RUB, } \\
\text { SGD, THB } \\
\text { AUD, BRL, CAD, } \\
\text { CLP, EUR, IDR, } \\
\text { ILS, JPY, KRW, } \\
\text { MXN, NZD, } \\
\text { NOK, PLN, ZAR, } \\
\text { CHF, GBP, USD }\end{array}$ & . & $\begin{array}{l}\text { COP, INR, IDR, } \\
\text { MYR, SGD, THB, } \\
\text { AUD, BRL, CAD, } \\
\text { CLP, CZK, EUR, } \\
\text { HUF, ILS, JPY, } \\
\text { KRW, MXN, NZD, } \\
\text { NOK, PLN, ZAR, } \\
\text { CHF, GBP, USD }\end{array}$ \\
\hline Total & 33 & - & 33 & - & 33 & - \\
\hline \multirow{2}{*}{$\begin{array}{c}\text { Exchange } \\
\text { rate regime } \\
\text { arrangements }\end{array}$} & \multicolumn{3}{|c|}{2010} & \multicolumn{3}{|c|}{2012} \\
\hline & Qty. & \multicolumn{2}{|c|}{ Currencies } & \multicolumn{3}{|c|}{ Currencies } \\
\hline Hard pegs & 0 & \multicolumn{2}{|l|}{ - } & \multicolumn{3}{|r|}{-} \\
\hline $\begin{array}{l}\text { Intermediate } \\
\text { exchange } \\
\text { rate regime }\end{array}$ & 7 & \multicolumn{2}{|c|}{$\begin{array}{c}\text { IRR, CNY, QAR, } \\
\text { SAR, AED, DKK, KWD }\end{array}$} & \multicolumn{3}{|c|}{$\begin{array}{l}\text { CNY, QAR, SAR, } \\
\text { AED, DKK, KWD }\end{array}$} \\
\hline $\begin{array}{l}\text { Floating } \\
\text { exchange } \\
\text { rate regime }\end{array}$ & 26 & \multicolumn{2}{|c|}{$\begin{array}{l}\text { AUD, BRL, CAD, CLP, } \\
\text { COP, EUR, ILS, JPY, KRW, } \\
\text { MXN, NZD, NOK, PLN, } \\
\text { ZAR, CHF, GBP, USD, } \\
\text { CZK, INR, IDR, PKR, RUB, } \\
\text { SGD, THB, MYR, HUF, }\end{array}$} & \multicolumn{3}{|c|}{$\begin{array}{l}\text { AUD, BRL, CAD, CLP, } \\
\text { COP, EUR, ILS, JPY, KRW, } \\
\text { MXN, NZD, NOK, PLN, } \\
\text { ZAR, CHF, GBP, USD, } \\
\text { CZK, INR, IDR, PKR, RUB, } \\
\text { SGD, THB, MYR, HUF, IRR }\end{array}$} \\
\hline Total & 33 & - & & 33 & & - \\
\hline
\end{tabular}

Notes: 1) There is no EUR in the IMF classification, the classification standard in 2004 and 2006 deemed 12 euro countries as the exchange rate countries without independent legal tender, and deemed the euro countries as those with independent floating exchange rate in 2008. Given that the Euro policy has no nominal anchor, it is considered as an independent floating currency. 2) In 2010 and 2012, IMF adjusted classification of the exchange rate regime. To keep consistency of analysis before and after it, only 3 major categories of classification were considered for each node.

Table 5. Cross-class changes in exchange rate policies.

\begin{tabular}{ccccc}
\hline Change directions & $2004 \rightarrow 2006$ & $2006 \rightarrow 2008$ & $2008 \rightarrow 2010$ & $2010 \rightarrow 2012$ \\
\hline $\begin{array}{c}\text { Intermediate exchange } \\
\text { rate regime } \rightarrow \text { floating } \\
\text { exchange rate regime }\end{array}$ & MYR & HUF & PKR, RUB & IRR \\
\hline $\begin{array}{c}\text { Floating exchange } \\
\text { rate regime } \rightarrow \text { intermediate } \\
\text { exchange rate regime }\end{array}$ & PKR, IRR & RUB & - & - \\
\hline
\end{tabular}


The currency fluctuations in this area were less related to that in others, and were mainly related with the exchange rate market in this area. It is noteworthy that the exchange rate fluctuations in the South American countries were not connected with the similar USD, but only to the MXN and CAD. Chile, Brazil and Mexico adopt the floating exchange rate regime.

b) Currencies of Africa and Australia

The currencies of South Africa, Australia and New Zealand were also on the edge of entire network. The South African currency ZAR connected only with the currencies of 3 European countries-Hungary, the Czech Republic and Poland. The Australian currency AUD connected with the currencies of New Zealand, Russia, Poland and Singapore. The New Zealand currency NZD connected only with those of Singapore and Australia. The exchange rate regime in these 3 countries adopts the independent floating system. While they were in the relatively marginalized location, the difference with the other two countries was that the location of Australia connected with countries in Asia and Europe, and in particular occupied one of the only 4 connections in Russia, reflecting that as a resource country, Australia has a central role in the economy and trade of the entire world. At same time, the structural characteristic of Australian dollar was similar to Japanese yen. It is also an arbitrage currency.

c) Currencies of Europe

As a whole, the degree centrality of each node in Europe is shown in Table 6.

Among them, the Danish currency DKK and the Czech currency CZK and the EUR were the 3 European currencies with most connections. The Russian currency RUB had the smallest degree of connections. It was worth noting that the four connections of RUB included the currencies of Singapore, Malaysia, India and Australia, instead of connecting directly with other European countries. It had no direct connection with the oil countries and USD, and was located at edge of the network, which indicates the Russia's relative independence of economy. For exchange rate regime, Russia adopted the management floating without prior publication of interventions $(2004,2006)$ and other traditional fixed-peg

Table 6. Degree centrality of currencies in Europe in static full-time network.

\begin{tabular}{cc}
\hline Currencies & Degree centrality \\
\hline DKK & 14 \\
CZK & 14 \\
EUR & 14 \\
PLN & 13 \\
HUF & 12 \\
NOK & 12 \\
CHF & 10 \\
GBP & 5 \\
RUB & 4 \\
\hline
\end{tabular}


system (2008) and then chose a more flexible exchange rate arrangement. Under the exchange rate arrangement with stronger overall floating, it was still connected with AUD, reflecting the stronger complementarity of the two resource countries. The U.K. pound's centrality was only 5 , reflecting decline of monetary market position of U.K. pound. The countries it connected included China, 3 Middle East oil countries and the United States, but it didn't have any direct connection with European countries. The degree centralities of several other European countries were high, and they had at least 10 connections.

From the perspective of internal connection of European currencies, Russian ruble and U.K. pound were not connected with other European currencies; the Swiss franc CHF was connected only with DKK and EUR; the other 6 currencies were interconnected, indicating a higher correlation between the major European currencies. The internal connections of European currencies are shown in Figure 6.

From an external connection perspective, European currencies were connected with USD, AED, SAR, and QAR, and were also more connected with KWD; among all currency connections with Asia (except West Asia), and they were all connected with CNY. Currencies connected with THB and PKR were EUR, CZK, DKK, and CHF, and those connected with JPY were HUF and PLN, but had no connection with other currencies in Asia. They had no connection with South American currencies; those connected with ZAR were NOK, PLN and HUF. It is worth noting that although JPY, THB and PKR have connections with European currencies, the connections with former and the latter two are completely different, and JPY didn't have any connection with other Asian currencies.

As one of the most developed economies in economy and trade in the world, Europe has stronger economic ties that are reflected in the highly connected exchange rate network. It is very closely connected with US and Middle East and relatively connected with some currencies in Asia (except West Asia). However, the connections are much weaker than that with US and Middle East.

d) Currencies of Asia (except West Asia)

From the internal connection perspective, the currencies in this area were more closely connected. JPY was in an isolated position, and IDR was connected with SGD only. The nodes that were located at more central were CNY, THB, PKR and MYR, as shown in Figure 7. For exchange rate regime, the RMB de

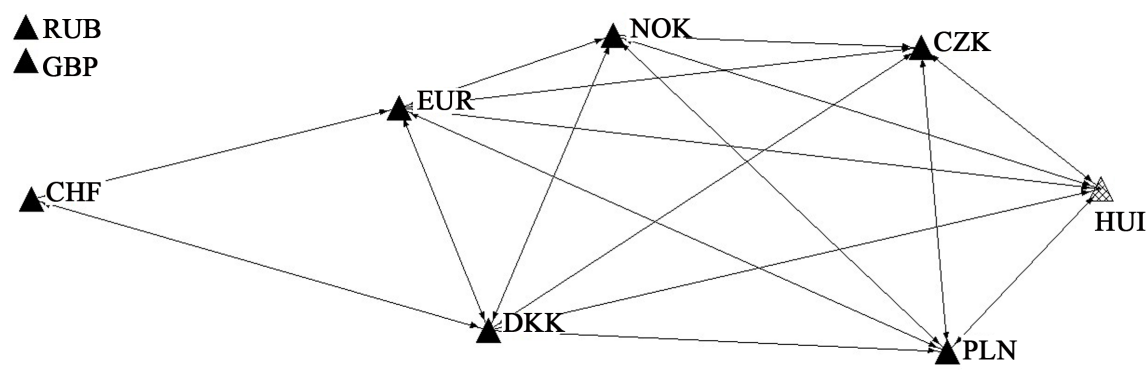

Figure 6. European internal connections in static full-time network. 


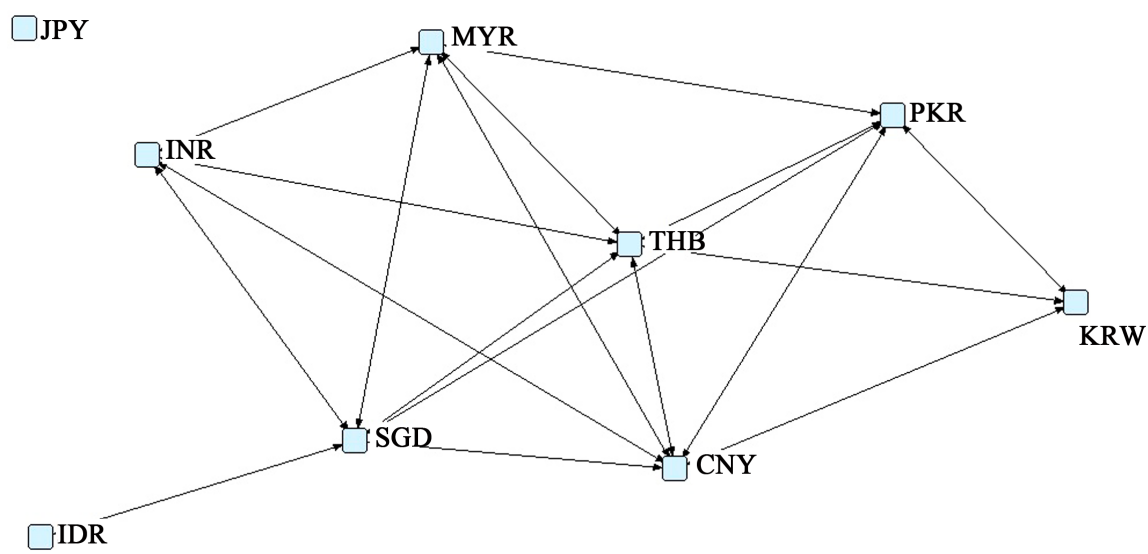

Figure 7. Intra-Asian connections in static full-time network.

facto exchange rate regime belonged to other traditional fixed-peg system that is pegged to USD prior to July 21, 2005 according to the IMF's classification standard. From July 1, 2005, China announced to implement the managed floating exchange rate regime based on market supply and demand with reference to a basket of currencies, but the exchange rate fluctuation of RMB against USD (3 months) was still within $2 \%$ from July 2005 to July 2006. According to the IMF's division standard, it is deemed that the de facto exchange rate regime of China remains the same. In 2007, the IMF classified China's exchange rate regime as a crawling pegging system. From 2003 to 2013, China's exchange rate regime still belonged to the intermediate exchange rate regime.

From the perspective of external connections: in connection with the European part, several Asian currencies such as KRW, SGD, MYR, INR and IDR were not directly connected to Europe. For other analysis, refer to the external analysis of European currencies. SGD was relatively special and connected with AUD and NZD. This is due to that Singapore is located at maritime throat of the Malacca Strait, and Singapore's position, as a bridge point between Asia and Oceania in the exchange rate network, reflects this information. All other currencies except IDR and JPY were connected with USD, SAR, and QAR. The West Asia node KWD was connected with all other Asian nodes except KRW, JPY and IDR and didn't contact with South American and African currencies. Position of CNY was more important in the network, and its centrality in the entire network was 19.

Asia (except West Asia) currencies had a closer internal connection; they were closely connected with West Asia and the United States; the connections with Europe were concentrated in the bridge point effect of CNY, PKR and THB; and the connections with Oceania were reflected in the bridge point effect of SGD; and they were not closely connected with South America and Africa.

e) Currencies of West Asia and North America

USD was at the center of entire network. With the exception of IRR and ILS, and $\mathrm{CAD}$, the currencies of the West Asia were very closely connected with the USD. The direct reason is that the exchange rate policy adopted in Saudi Arabia, 
Qatar, Kuwait and the UAE belongs to other traditional fixed-peg system that is pegged to USD, and that these currencies show a high consistency. The degree centrality of each node in West Asia and North America is shown in Table 7.

For the two nodes with zero centrality, Israeli ILS adopted the independent floating exchange rate regime (2004, 2006 and 2008), the Iranian IRR adopted the management floating without prior publication of interventions (2004) and the crawling pegging exchange rate regime that is pegged to a basket of currencies $(2006,2008)$.

To sum up, correlation network of exchange rate fluctuation reflects stronger geographical characteristics: except Africa and North America, the correlation of internal currency fluctuation in other areas was strong; because of the developed economy and trade, there are stronger external correlations among Europe, Asia (except West Asia), West Asia and North America; the exchange rate network and exchange rate policy arrangements are strongly correlated, in particular, as the CNY, AED, SAR, and QAR in the network used the de facto exchange rate regime that is pegged to USD, which enables these 4 nodes to show the same network nature to USD in the full-time static network. Under the full-time series, correlation coefficients of CNY, AED, SAR, QAR and the USD return rate time series are: $0.9288,0.9929,0.9965$, and 0.9968 . Around USD, the capacity currencies represented by RMB and the oil currencies in Middle East have formed a core area in the world currency pattern. This characteristic also reflects the absolute central position of USD in the exchange rate network.

\section{Conclusions and Suggestions}

In transferring time series into network by the threshold method, the threshold reflects the trade-off between the retaining of the overall system information and presentation of those more important related information. The larger the threshold is, the more the subordinate information is deleted, and the more obvious the key related information is in the network. In the event of reasonably preserving the integrity of the system information and simultaneously considering the power law of the network degree distribution, the optimal threshold will be

Table 7. Degree centrality of West Asian and North American currencies in static full-time network.

\begin{tabular}{cc}
\hline Currencies & Degree centrality \\
\hline USD & 19 \\
SAR & 19 \\
AED & 19 \\
QAR & 19 \\
KWD & 15 \\
CAD & 1 \\
ILS & 0 \\
IRR & 0 \\
\hline
\end{tabular}


obtained. Under the optimal threshold, transferring the numerous related time series into a network, the real related structure features will emerge.

Based on the optimal threshold, analyzing the exchange rate network of major currencies, it is found that the major international currencies show an obvious community structure. Around USD, the RMB-denominated capacity currency and the West Asia oil currency have formed a core area; peripheries are the demand-based currencies of mid-low end manufacturing products in Europe and the resource currencies represented by Indonesian rupiah and Australian dollar. Korean won and pound are in shadow currency position in the entire network structure. Meanwhile, the Australian dollar and Japanese yen have similar structures if New Zealand dollar isn't considered. As arbitrage behavior has weakened the connection between the two major currencies and other major currencies, it can be considered that the two currencies have the arbitrage function. The difference is that the Australian dollar arbitrage is dominated by the resource and core area currencies, while the Japanese yen arbitrage is dominated by the core area currency and demand-type currency, which should be given enough attention. The choice of exchange rate regime in countries is the result of the differences in economic development, economic systems and the characteristics of international trade, as well as the result of this country currency's location choice in the international monetary system.

USD had always occupied the core status of network, but its core status had declined to some extent after the financial crisis occurred. With the gradual recovery of the U.S. economy from impact of financial crisis, its core status has rebounded to some extent. As China is facing the transformation of social and economic structures, the internal pressure becomes increasingly prominent, and the relatively stable exchange rate of RMB is very important. From the external perspective, stability of the RMB exchange rate that is one of the core associated nodes also helps maintain the sound development of international economy and trade. Therefore, implementation of a managed floating exchange rate regime is necessary, as well as an expression of international responsibility of a great power. At same time, the long-term one-way changes of RMB, an associated core node, has a significant impact on the order of international monetary market. Under the current economic and trade patterns, maintaining stability of exchange rate structure is the unanimous demand of all countries in the world. Therefore, RMB doesn't have the conditions of long-term devaluation under the premise of smooth operation of the domestic politics and economy.

\section{Acknowledgements}

The research is supported by National Natural Science Foundation of China (No.71371200, 71071167).

\section{Conflicts of Interest}

The authors declare no conflicts of interest regarding the publication of this paper. 


\section{References}

[1] Jackson, M.O. (2008) Social and Economic Networks. Princeton University Press, Princeton, NJ, 44-74.

[2] Yang, J. (2010) Comparison of Research Paradigms between Complex Network and Social Network. Systems Engineering-Theory \& Practice, 30, 2046-2055.

[3] Mitchell, J.C. (1969) The Concept and Use of Social Networks. Social Networks in Urban Situations.

[4] Scott, J. (1991) Social Network Analysis: A Handbook. Contemporary Sociology, 22, 128. https://doi.org/10.2307/2075047

[5] Granovetter, M.S. (1973) The Strength of Weak Ties. American Journal of Sociolo$g y$, 78, 1360-1380. https://doi.org/10.1086/225469

[6] Cohen, L., Frazzini, A. and Malloy, C. (2008) The Small World of Investing: Board Connections and Mutual Fund Returns. Journal of Political Economy, 116, 951-979. https://doi.org/10.1086/592415

[7] Zhang, M., Tong, L. and Xu, H. (2015) Social Networks and Corporate Risk-Taking-Based on the Empirical Evidence of China's Public Companies. Management World, No. 11, 161-175.

[8] Watts, D.J. and Strogatz, S.H. (1998) Collective Dynamics of "Small-World" Networks. Nature, 393, 440-442. https://doi.org/10.1038/30918

[9] Barabasi, A.L. and Albert, R. (1999) Emergence of Scaling in Random Networks. Science, 286, 509-512. https://doi.org/10.1126/science.286.5439.509

[10] Glasserman, P. and Young, H.P. (2015) How Likely Is Contagion in Financial Networks? Journal of Banking \& Finance, 50, 383-399. https://doi.org/10.1016/j.jbankfin.2014.02.006

[11] Yan, Y., Yin, L., Li, X. and Chen, X. (2015) The U.S. Economy Is Controlled by Wall Street-The Enlightenment to the Development of State-Owned Capital Investment Company in China. Management World, No. 6, 1-7.

[12] Nier, E., Yang, J., Yorulmazer, T. and Alentorn, A. (2007) Network Models and Financial Stability. Journal of Economic Dynamics and Control, 31, 2033-2060. https://doi.org/10.1016/j.jedc.2007.01.014

[13] Li, Y., Cao, H. and Xing, H. (2012) Modeling and Simulation of Complex Finance Networks Based on Minority Game. Systems Engineering-Theory \& Practice, 32, 1882-1890.

[14] Li, Z., Liang, Q. and Tu, X. (2016) The Connectedness of Chinese Listed Financial Institutions: A Study Based on Network Analysis. Journal of Financial Research, 434, 95-110.

[15] Zhang, L., Yang, Z. and Lu, F. (2014) Empirical Analysis of Relevance of Stock Indicators Based on Complex Network Theory. Chinese Journal of Management Science, 22, 85-92.

[16] Mantegna, R.N. (1999) Hierarchical Structure in Financial Markets. The European Physical Journal B: Condensed Matter and Complex Systems, 11, 193-197. https://doi.org/10.1007/s100510050929

[17] Johnson, N.F., McDonald, M., Suleman, O., Williams, S. and Howison, S. (2005) What Shakes the FX Tree? Understanding Currency Dominance, Dependence and Dynamics. Physics, 12, 618-875. https://doi.org/10.1117/12.618875

[18] Naylor, M.J., Rose, L.C. and Moyle, B.J. (2007) Topology of Foreign Exchange Markets Using Hierarchical Structure Methods. Physica A: Statistical Mechanics \& Its 
Applications, 382, 199-208. https://doi.org/10.1016/j.physa.2007.02.019

[19] Keskin, M., Deviren, B. and Kocakaplan, Y. (2011) Topology of the Correlation Networks among Major Currencies using Hierarchical Structure Methods. Physica A: Statistical Mechanics \& Its Applications, 390, 719-730.

https://doi.org/10.1016/j.physa.2010.10.041

[20] Boginski, V., Butenko, S. and Pardalos, P.M. (2005) Statistical Analysis of Financial Networks. Computational Statistics \& Data Analysis, 48, 431-443. https://doi.org/10.1016/j.csda.2004.02.004

[21] Kwapień, J., Gworek, S., Drożdż, S. and Górski, A. (2009) Analysis of a Network Structure of the Foreign Currency Exchange Market. Journal of Economic Interaction \& Coordination, 4, 55. https://doi.org/10.1007/s11403-009-0047-9

[22] Albert, R. and Barabasi, A.-L. (2001) Statistical Mechanics of Complex Networks. Physics, 74, 47. https://doi.org/10.1103/RevModPhys.74.47

[23] Cao, H., Li, Y. and Chen, Y. (2013) Stock Correlation Network Based on Optimal Threshold Value-Take the Shanghai A-share Market as an Example. International Conference on Financial Engineering, Hangzhou, China.

[24] Krugman, P. (1999) The Return of Depression Economics. Foreign Affairs, 78, 56-74.

[25] IMF, (2004, 2006, 2008, 2010, 2012) International Monetary Fund Annual Report.

[26] Hagen, V. and Zhou, J.Z. (2007) The Choice of Exchange Rate Regimes in Developing Countries: A Multinomial Panel Analysis. Study of Finance \& Economics, 26, 1071-1094. https://doi.org/10.1016/j.jimonfin.2007.05.006 